Pecvnia, 4 (2007), pp. 171-199

\title{
La reestructuración de la minería leonesa
}

\author{
Jesús Sánchez Melado \\ jesus@eurl-va.org \\ Escuela Universitaria de Relaciones Laborales \\ $\mathrm{c} / \mathrm{Olmo}, 63$ \\ 47010 Valladolid (España)
}

\begin{abstract}
Este artículo analiza los cambios más importantes que han tenido lugar en la minería leonesa a lo largo del proceso de reordenación iniciado en 1990. Entre ellos cabe destacar la reducción de la capacidad de producción, la contracción de las plantillas, la mejora de los rendimientos, la contención de costes y la profunda transformación de su estructura empresarial. Pese a ello, el gran problema de la industria carbonera leonesa sigue siendo el de su inviabilidad. La incertidumbre derivada de este problema se ha visto además acrecentada con la entrada en vigor de las nuevas normas tendentes a moderar las emisiones contaminantes a la atmósfera.
\end{abstract}

Palabras clave: minería, carbón, crisis, reestructuración
This article analyzes the most important changes that they have taken place in the mining in Leon throughout the process of rearrangement initiated in 1990. Among them it is possible to emphasize the reduction of the production capacity, the contraction of the employment, the improvement of the yields, the containment of costs and the deep transformation of its enterprise structure. In spite of it, the great problem of the coal industry in Leon continues being its inviabilidad. The uncertainty that this problem causes has been increased with the take effect of the new norms to diminish the polluting emissions to the atmosphere.

Key words: mining, coal, crisis, reorganization 


\section{LAS LÍNEAS GENERALES DE LA REORDENACIÓN CARBONERA}

A mediados de los años ochenta, una serie de acontecimientos -el fin de la crisis energética, el cambio tecnológico, las normas de protección ambiental y la necesidad de adaptar los precios y las ayudas públicas a la normativa comunitaria- marcaron el comienzo de un titubeante proceso de reestructuración de la minería nacional del carbón, un proceso aún en marcha y de incierto resultado final. Su primera manifestación fue el Nuevo Sistema de Contratación del Carbón Térmico (NSCCT), convenio marco, visado por la Administración, que Carbunión y Unesa firmaron el 10 de diciembre de 1986.

Al obligar a las empresas a mejorar su eficiencia o a disminuir su actividad, el NSCCT contenía ya un mecanismo dirigido a la reordenación de la minería del carbón. Pero se trataba de un mecanismo ineficiente. En efecto, la viabilidad se definía comparando los costes con el denominado precio de referencia, un precio muy superior al vigente en el mercado mundial. De esta forma, el grupo de empresas consideradas viables estaba formado, en realidad, por productores no competitivos, a los que el sistema no obligaba a realizar los necesarios esfuerzos en pos de una mayor eficiencia. La intensidad de la reestructuración iba a ser, por tanto, mínima; y el número de empresas afectado por ella, claramente insuficiente.

La Tabla 1 proporciona una imagen de la situación económica de la industria carbonera leonesa en 1989, tras tres años de aplicación del NSCCT. Destaca, en primer lugar, el hecho de que el conjunto de las empresas del sector registrara unas pérdidas cercanas a los 7.000 millones de pesetas. No menos llamativo resulta el hecho de que el signo negativo de los resultados predominara claramente en el grupo de las 25 mayores empresas. Sólo dos (la Vasco-Leonesa y Antracitas de Matarrosa) consiguieron beneficios significativos, otras cinco obtuvieron ganancias pero de escasa cuantía, y el 72 por 100 restante (18 empresas) cosechó pérdidas que deben ser calificadas como notables tanto por su importe absoluto como por su efecto en los fondos propios de las compañías. La idea de que también las empresas de mayor tamaño se encontraban en una situación crítica se confirma al analizar el grupo formado por las siete principales: si excluimos a la Vasco-Leonesa (la única con beneficios), las pérdidas de las demás oscilaron entre el 40 y el 288 por 100 de sus respectivos patrimonios netos. 
Tabla 1. Patrimonio neto, resultados y plantillas en 1989 de las empresas carboneras leonesas

\begin{tabular}{|c|c|c|c|c|c|}
\hline Empresa & Cuenca & $\begin{array}{c}\text { Suministros } \\
\text { subterráneos } \\
\text { (miles } \\
\text { toneladas) }\end{array}$ & Plantilla & $\begin{array}{c}\text { Patrimonio } \\
\text { neto }(*)\end{array}$ & $\begin{array}{c}\text { Resultado } \\
\text { (*) }\end{array}$ \\
\hline MSP (Villablino) & Villablino & 1.029 & 2.721 & $3.006,0$ & $-2.415,0$ \\
\hline Vasco-Leonesa & Ciñera-Matallana & 977 & 1.599 & $10.244,8$ & $1.234,5$ \\
\hline Antracitas Gaiztarro & El Bierzo & 400 & 866 & $1.106,9$ & $-441,4$ \\
\hline Hulleras de Sabero & Sabero & 253 & 960 & $1.503,2$ & $-1.004,1$ \\
\hline Antracitas del Bierzo & El Bierzo & 138 & 424 & $-2.276,0$ & $-854,7$ \\
\hline Combustibles de Fabero & El Bierzo & 137 & 333 & 203,2 & $-585,5$ \\
\hline Antracitas de Fabero & El Bierzo & 108 & 463 & $-1.018,7$ & $-721,8$ \\
\hline Antracitas de Matarrosa & El Bierzo & 103 & 118 & 480,5 & 254,9 \\
\hline Alto Bierzo & El Bierzo & 90 & 210 & 274,4 & $-21,0$ \\
\hline Viloria Hermanos & El Bierzo & 83 & 200 & $1.029,2$ & 50,9 \\
\hline Campomanes Hermanos & El Bierzo & 76 & 173 & 54,3 & $-31,5$ \\
\hline Victoriano González & El Bierzo & 72 & 164 & 96,2 & $-126,3$ \\
\hline Minex & El Bierzo & 63 & 191 & 221,4 & 2,6 \\
\hline Carbones Montealegre & El Bierzo & 63 & 95 & $-24,6$ & $-136,7$ \\
\hline Antracitas de Besande & Valderrueda & 55 & 132 & $-205,8$ & $-281,1$ \\
\hline Antracitas de Brañuelas & El Bierzo & 52 & 286 & 386,0 & $-22,3$ \\
\hline Carbonia+Busdongo & Cármenes-Villam. & 51 & 101 & 119,6 & 3,8 \\
\hline Antracitas de La Granja & El Bierzo & 51 & 83 & 65,3 & 0,5 \\
\hline Minas Leonesas de Espina & El Bierzo & 51 & 190 & $-191,4$ & $-208,4$ \\
\hline Antracitas de Marrón & El Bierzo & 50 & 193 & $-703,7$ & $-313,0$ \\
\hline Hijos de Baldomero García & Villablino & 50 & 195 & 152,9 & $-49,8$ \\
\hline Carbones San Antonio & El Bierzo & 48 & 160 & 20,7 & $-124,2$ \\
\hline Antracitas del Salgueiro & El Bierzo & 47 & 106 & 97,1 & 1,6 \\
\hline Minera Peñarrosas & El Bierzo & 46 & 74 & 56,1 & $-19,5$ \\
\hline Mina Carmen & La Magdalena & 41 & 81 & $-203,4$ & $-62,9$ \\
\hline \multicolumn{2}{|l|}{ Totales 25 empresas } & 4.134 & 10.118 & $14.494,2$ & $-5.870,4$ \\
\hline \multicolumn{2}{|l|}{ Resto (60 empresas) } & 874 & 1.999 & 317,3 & $-978,5$ \\
\hline \multicolumn{2}{|l|}{ Totales León } & 5.008 & 12.117 & $14.811,5$ & $-6.848,9$ \\
\hline
\end{tabular}

(*) Millones de pesetas.

Nota: El documento utilizado como fuente no suministra los datos del patrimonio neto y resultados de todas las empresas con suministros inferiores a 40.000 toneladas. Los que faltan corresponden a algunas de las compañías de menor dimensión (suministros por debajo de 12.000 toneladas), por lo que su ausencia no distorsiona de manera significativa los totales provinciales.

Fuente: Documento sin fecha de la Comisión de Seguimiento del NSCCT (Archivo de la Fundación de la Sociedad Hullera Vasco-Leonesa).

Una circunstancia adicional, que completa el delicado escenario en el que se desenvolvía la minería leonesa al terminar la década de los ochenta, surge al comprobar que la desfavorable evolución iniciada en 1985 había llevado, en tan sólo cuatro años, a siete empresas a una situación técnica de quiebra. Los abultados patrimonios negativos de Antracitas del Bierzo, Antracitas de Fabero, Antracitas de Besande, Minas 
Leonesas de Espina, Antracitas de Marrón, Mina Carmen y (en menor medida) Carbones Montealegre, no permitían albergar prácticamente ninguna esperanza sobre su continuidad. Por lo demás, si los resultados no mejoraban se encontrarían en la misma situación otras seis empresas dentro del plazo de los dos años siguientes, entre ellas MSP y Hulleras de Sabero. Las plantillas de las trece compañías abocadas más claramente al cierre totalizaban 6.089 trabajadores, la mitad del empleo generado por la industria carbonera leonesa.

El evidente fracaso del NSCCT quedó plenamente confirmado cuando en 1989 las ayudas a los productores privados (suplementos de precio), en lugar de disminuir como estaba previsto, tuvieron que aumentar debido al crecimiento de las pérdidas de las empresas. Ante los exiguos frutos conseguidos y las presiones de la Comisión Europea, el Gobierno español no tuvo más remedio que poner en marcha la reordenación «oficial» de la industria del carbón. Desde sus inicios en 1990, se han sucedido cuatro planes:

- El Plan de Reordenación del Sector del Carbón (1990-1993).

- El Plan de Modernización, Racionalización, Reestructuración y Reducción de Actividad de la Industria del Carbón (1994-1997).

- El Plan 1998-2005 de la Minería del Carbón y Desarrollo Alternativo de las Comarcas Mineras (Plan del Carbón).

- El Plan Nacional de Reserva Estratégica de Carbón 2006-20012 y Nuevo Modelo de Desarrollo Integral y Sostenible de las Comarcas Mineras.

Aunque existen significativas diferencias entre ellos, todos comparten un concepto de viabilidad que les resta eficacia, y que ha desembocado en el mantenimiento de empresas incapaces de competir sin ayudas o, incluso, con una moderada protección. En otras palabras, de una u otra forma, han reproducido el ineficiente mecanismo del NSCCT.

Los aspectos más positivos aparecen asociados al Plan del Carbón (debido a su reciente aprobación, no es posible aún analizar los efectos del Plan Nacional de Reserva Estratégica). Entre ellos cabe destacar la aplicación de los precios vigentes en el mercado mundial a las transacciones internas, la consiguiente transparencia de las ayudas públicas y la supresión de las restricciones cuantitativas a las importaciones, sustituidas por la obligación de las centrales térmicas de asumir unos compromisos mínimos de compra de carbón nacional. Durante su vigencia 
se ha llevado a cabo el grueso del recorte de la capacidad productiva, apenas aminorada durante las dos fases anteriores. De la misma forma, la reactivación de las comarcas mineras recibió un considerable impulso en 1998, si bien ya dos años antes la política de desarrollo alternativo había alcanzado una mayor consistencia.

Entre 1998 y 2005, las diferentes ayudas concedidas por la Administración central a la industria carbonera de Castilla y León han totalizado casi 4.000 millones de euros. Las más cuantiosas han sido las destinadas a financiar las prejubilaciones y las bajas incentivadas, que han ascendido a 1.630 millones de euros. El montante de las subvenciones para cubrir pérdidas de explotación ha sido similar: 1.562 millones de euros.

Además de las subvenciones, directas o indirectas, de la Administración central a la industria carbonera, la reordenación entraña dos costes adicionales para las arcas públicas: el correspondiente al Plan de Desarrollo Alternativo de las Comarcas Mineras (sufragado por la Administración central) y el relativo al Programa de Actuación Minera de la Junta de Castilla y León. Entre 1998 y 2005, las intervenciones del primero ascendieron aproximadamente a 900 millones de euros; y las del segundo, a 340 millones ${ }^{1}$. Así pues, podemos estimar en más de 5.000 millones de euros el montante de las ayudas públicas que, durante los ocho años del Plan del Carbón, han servido de apoyo a la minería regional y a las comarcas afectadas por la reestructuración.

Como consecuencia del ajuste, tanto la industria carbonera como los territorios donde se asienta han experimentado notables transformaciones. En los epígrafes siguientes nos centraremos en los cambios que han acontecido en la minería leonesa desde 1990, unos cambios que, además de afectar a la capacidad de producción y la eficiencia de las explotaciones, han desembocado en una profunda alteración de la estructura empresarial de la industria carbonera provincial. Dado que las únicas variedades de carbón que se obtienen en la provincia son la hulla y la antracita, todas las alusiones a la industria nacional deben entenderse referidas únicamente a este segmento del mercado. 


\section{EL LENTO AJUSTE DE LA CAPACIDAD PRODUCTIVA DE LAS MINAS LEONESAS}

La inconsistencia, una de las características más evidentes de la reconversión carbonera, es especialmente perceptible en León, donde, contrariamente a lo acontecido en Asturias, el déficit de explotación de las empresas mineras no parece haber sido motivo suficiente para acometer un recorte sustancial de la producción hasta fechas relativamente recientes (Figura 1). De modo que, mientras la industria nacional de la hulla y la antracita rebajaba un 41 por 100 su capacidad de extracción entre 1989 y 2005, la minería leonesa lo hacía simplemente un 26 por 100. Una disminución que, además, no comenzó a hacerse realidad hasta 1998, puesto que durante la vigencia de los dos primeros planes de reestructuración la producción leonesa de carbón aumentó un 12 por 100.

Figura 1. Evolución de la producción leonesa de carbón, 1989-2005 (miles de toneladas)

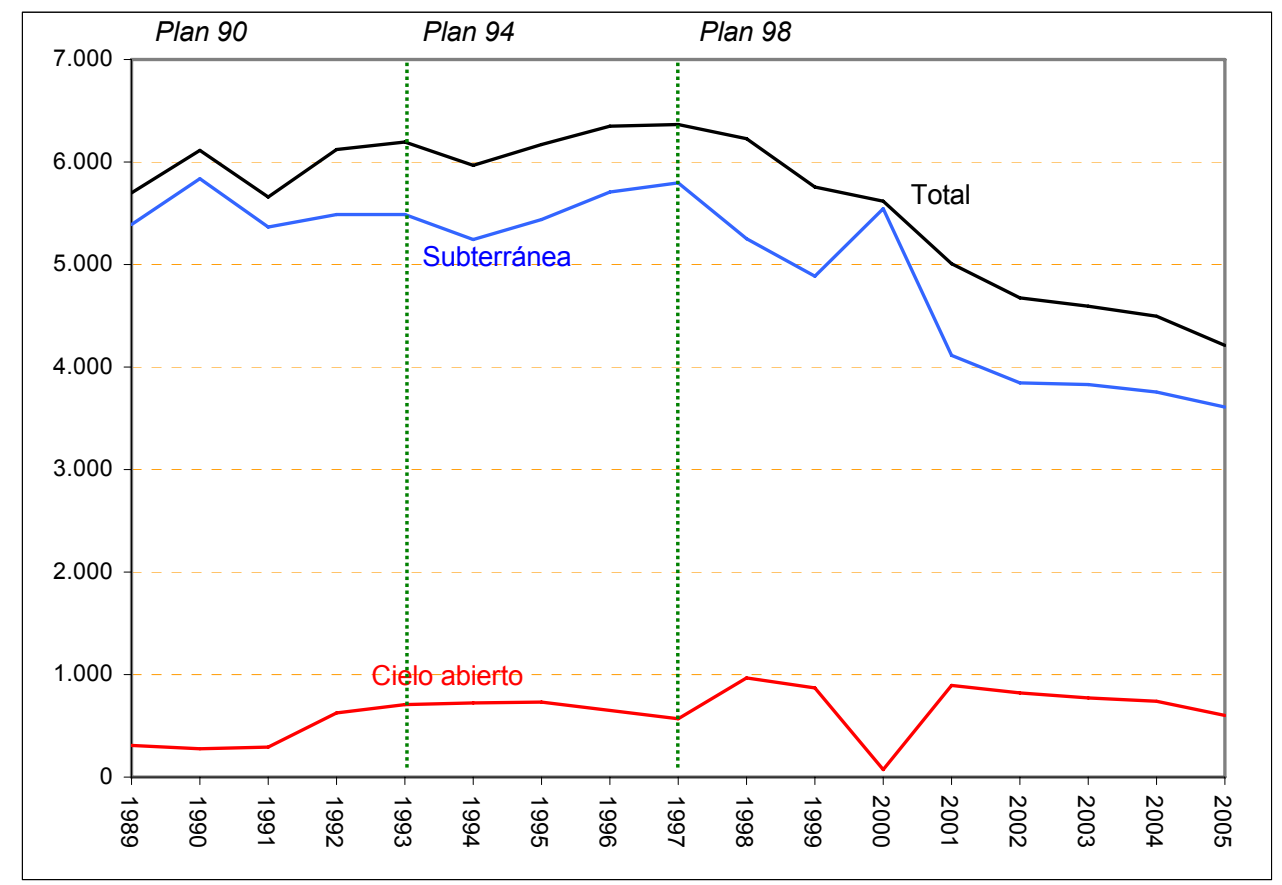

Fuente: IRMC.

Es precisamente al analizar la producción cuando más claramente se pone de manifiesto la contradictoria naturaleza de la reestructuración de la industria del carbón, puesto que la evolución 
observada hasta 1997 sólo fue posible porque se permitió que empresas no competitivas aumentaran sus suministros, algo, en principio, difícilmente compatible con el saneamiento económico del sector.

En descargo parcial de una política en apariencia tan poco coherente, cabe esgrimir el período de sequía que se inició en nuestro país en 1989 y que se prolongaría hasta finales de 1995. Dadas las restricciones introducidas en el sistema eléctrico por decisiones como la moratoria nuclear, la menor generación hidroeléctrica motivada por las condiciones climáticas -contrarrestada parcialmente por el débil crecimiento de la demanda de energía eléctrica ocasionado por la crisis económica - tuvo que ser suplida con una mayor utilización de las centrales térmicas convencionales, con el consiguiente aumento de la demanda de carbón.

Esta circunstancia resultó especialmente relevante para la minería leonesa, que tiene en las cuatro centrales térmicas de la región su soporte fundamental. Lo demuestra el hecho de que su consumo (Figura 2) superara, salvo en $1996^{2}$, a la producción leonesa y palentina de hulla y antracita, pese a lo cual, hasta 1997, sólo la central de Guardo se vio obligada a importar mineral ${ }^{3}$. En esta especie de mercado cautivo que el parque termoeléctrico representa para el carbón leonés y palentino, radica la única garantía de su continuidad. Pero el problema que plantea el mantenimiento de esta situación es el de los elevados costes de generación que el combustible empleado supone para las citadas centrales.

Las causas explicativas de la evolución de la producción leonesa hasta 1997 no estarían completas sin mencionar que su incremento se concentró en las dos empresas más importantes de la provincia: MSP y la Vasco-Leonesa. Especialmente en la primera, cuya producción creció en 628.000 toneladas por efecto del plan de viabilidad que pretendía sacarla de la quiebra. El carbón extraído por la Vasco-Leonesa aumentó en 186.000 toneladas.

En la tercera fase de la reestructuración, la situación varió sustancialmente. Pero el cambio no aconteció en el primer año del Plan del Carbón, sino a partir de 1999. En 1998, la notable reducción de la

\footnotetext{
2 Las elevadas precipitaciones de 1996 ocasionaron la caída del consumo de carbón que se observa ese año, pero las compras de mineral realizadas por las térmicas no disminuyeron, sino que aumentaron un 3 por 100, lo que dio lugar a un aumento de sus existencias.

3 Las importaciones de carbón de la central de Guardo ascendieron a 18.000 toneladas en 1994, 59.000 en 1995, 66.000 en 1996 y 123.000 en 1997.
} 
producción subterránea, realizada fundamentalmente al amparo de las ayudas para cubrir cargas excepcionales, fue contrarrestada en gran parte con un incremento de la actividad en las destrozas. Aprovechando las mencionadas ayudas, el recorte de la capacidad extractiva se llevó a cabo en su mayor parte entre 1999 y 2002; en contrapartida, las empresas de la región se embolsaron 110 millones de euros en concepto de pérdidas de activos, una media de 75 euros por tonelada.

Figura 2. Consumo de carbón en las térmicas de Castilla y León, 1989-2005 (miles de toneladas)

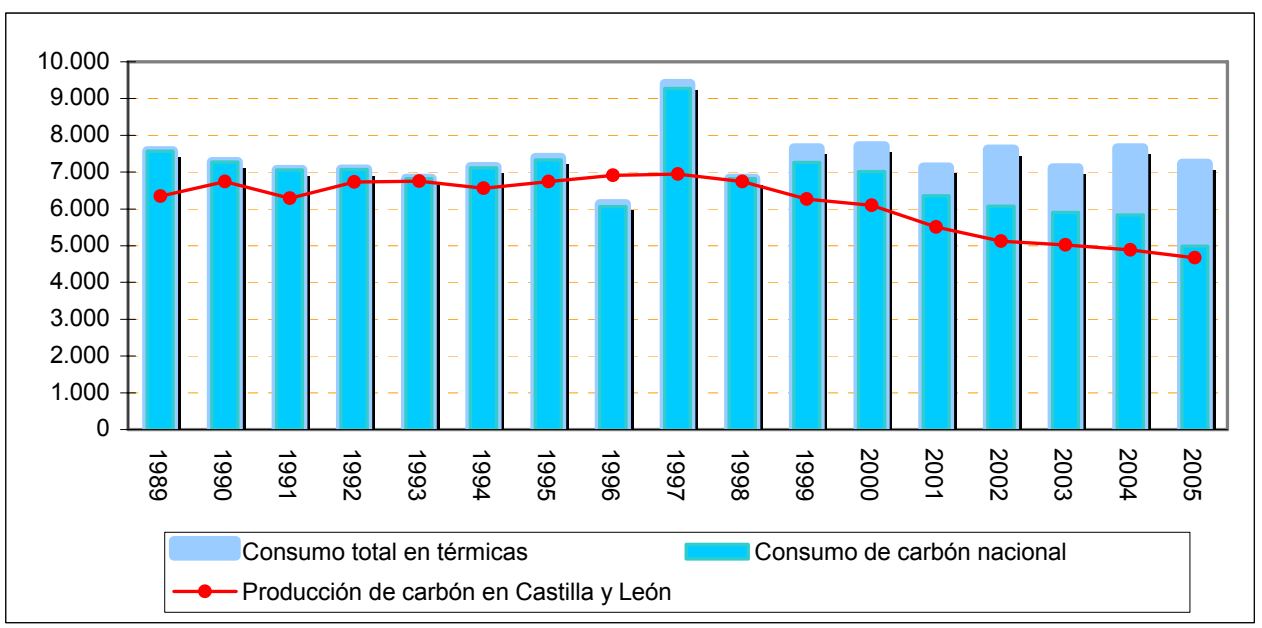

Nota: La fuente utilizada no desglosa el carbón consumido en 1998.

Fuente: Estadística Energética de Castilla y León.

Después de 2002, se observa una clara ralentización del ajuste. Aun así, durante la vigencia del Plan del Carbón, la producción leonesa ha disminuido un 34 por 100, pese a lo cual su peso en la industria nacional de la hulla y la antracita se ha mantenido prácticamente constante alrededor del 50 por 100. Dicho de otra forma, a lo largo de esta etapa la capacidad extractiva provincial se ha contraído al mismo ritmo que la media.

En el terreno del empleo es donde verdaderamente ha resultado contundente la reestructuración de la minería leonesa. Su plantilla se contrajo un 78 por 100 entre 1989 y 2005 -porcentaje similar al nacional-, quedando reducida a poco más de 2.600 trabajadores. El costoso sistema de las prejubilaciones ha sido el mecanismo utilizado para aligerar de manera no traumática las plantillas mineras. 
Lógicamente, a tenor de las evoluciones respectivas de la producción y las plantillas, los efectos de la reestructuración sobre los rendimientos de las minas leonesas han sido sobresalientes: las 470 toneladas anuales por trabajador conseguidas en 1989 se han multiplicado por 3,4 para transformarse en 1.600 en 2005 . Este proceso de mejora sólo se detuvo durante la primera mitad del Plan del Carbón, un período de intensa reducción de la producción.

El avance ha sido posible, en parte, porque las explotaciones a cielo abierto han aumentado tanto su importancia relativa como sus propios rendimientos. De esta forma, en León la actividad en las destrozas se ha multiplicado por dos, cuando a escala nacional el crecimiento registrado ha sido simplemente del 5 por 100 . Queda así patente el progresivo aumento del impacto de la actividad carbonera en el medio ambiente de una provincia donde el mineral obtenido a cielo abierto ha pasado de representar el 5,4 por 100 a suponer el 14,2 por 100 de la producción. Por su parte, los rendimientos en las cortas se han elevado desde 2.567 hasta 6.799 toneladas anuales por trabajador, es decir, un 165 por 100 .

No obstante, el factor decisivo a la hora de explicar el incremento de la eficiencia ha sido la mejora de las explotaciones subterráneas, cuyos rendimientos han progresado un 216 por 100, hasta situarse en 1.419 toneladas anuales por trabajador en 2005.

La eficiencia de la minería leonesa es incomparablemente más elevada que la de la minería pública (283 toneladas anuales por trabajador en 2005), pero resulta inferior a la del resto de los productores privados de hulla y antracita. En 2004, por ejemplo, los rendimientos de éstos superaban a los leoneses en un 33 por 100. Este hecho no es más que el reflejo del mayor peso que las labores a cielo abierto tienen en las cuencas de Córdoba y Ciudad Real, donde prácticamente todo el carbón procede en la actualidad de las destrozas.

Como es lógico, detrás del avance registrado por los rendimientos se encuentra la evolución de las inversiones (Figura 3). En general, la cuantía total de las inversiones leonesas siguió una tendencia creciente durante las dos primeras fases de la reestructuración. Esto hizo que la inversión media se situara en 49,7 millones de euros anuales, un 74 por 100 por encima del esfuerzo desplegado en los últimos años de la década de los ochenta. La negativa evolución que se observa en 2002 y 2003 se debe, en parte, a la incertidumbre generada por factores como la 
expiración de la CECA, el diseño del nuevo sistema de ayudas y las normas ambientales aplicables a las centrales térmicas.

Figura 3. Inversiones en la minería leonesa (miles de euros), 1989-2003

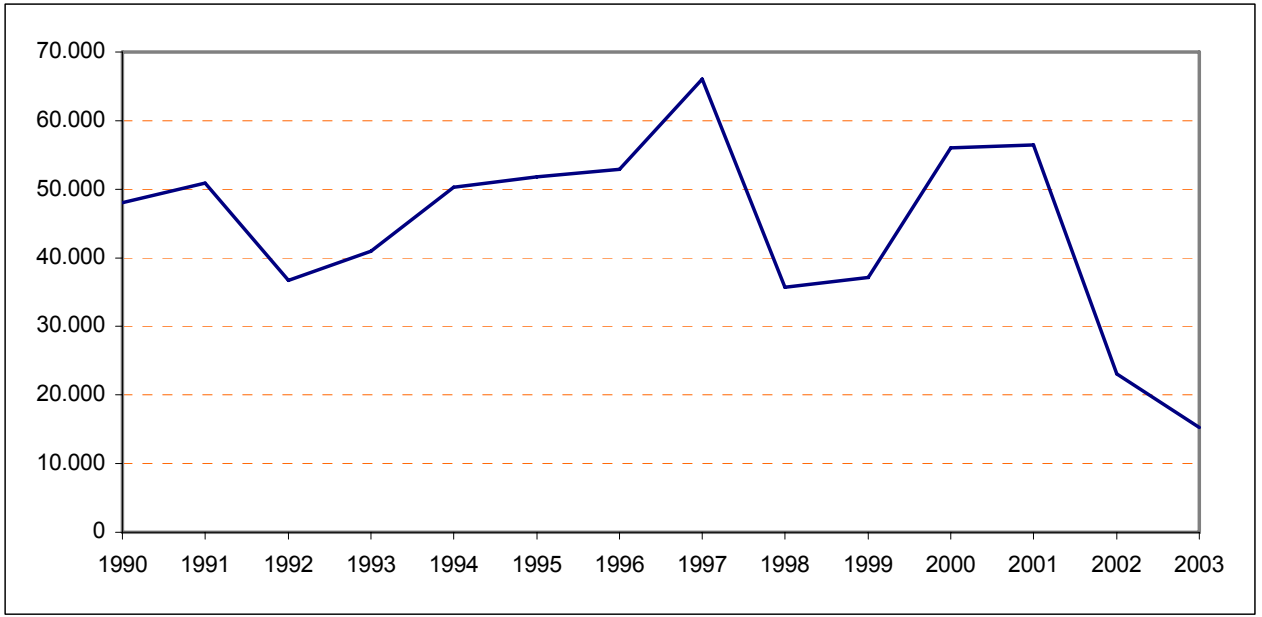

Fuente: Estadística Minera de España.

Los efectos de la reordenación también se han dejado notar en los costes de producción. La Figura 4 pone de manifiesto la contención experimentada por los costes medios (esto es, su reducción en términos reales). De hecho, según la Estadística Minera de España (fuente que no da cuenta de todos los costes de las empresas mineras), en 2003 costaba casi un 5 por 100 menos extraer una tonelada de hulla que en 1990 . Un resultado que se ha conseguido gracias a que, tras experimentar una continua mengua, los costes de personal por tonelada se situaron en 2003 un 25 por 100 por debajo de su nivel en 1989. Éste fue el resultado de un incremento mayor de los rendimientos (168 por 100 hasta 2003) que de las retribuciones medias (101 por 100). Como contrapartida, al igual que en el conjunto de la industria nacional, la sustitución de trabajo por capital y la subcontratación de las labores han hecho que la cuantía del resto de los costes, globalmente considerados, haya seguido una tendencia ascendente.

En suma, el proceso de reordenación ha ocasionado una moderada contracción de la capacidad productiva de la minería leonesa $\mathrm{y}$, sobre todo, un apreciable aumento de su eficiencia, que se refleja en el crecimiento de los rendimientos y en la contención de los costes de extracción. 
Figura 4. Costes medios de producción en la minería leonesa (euros/tonelada), 1989-2003

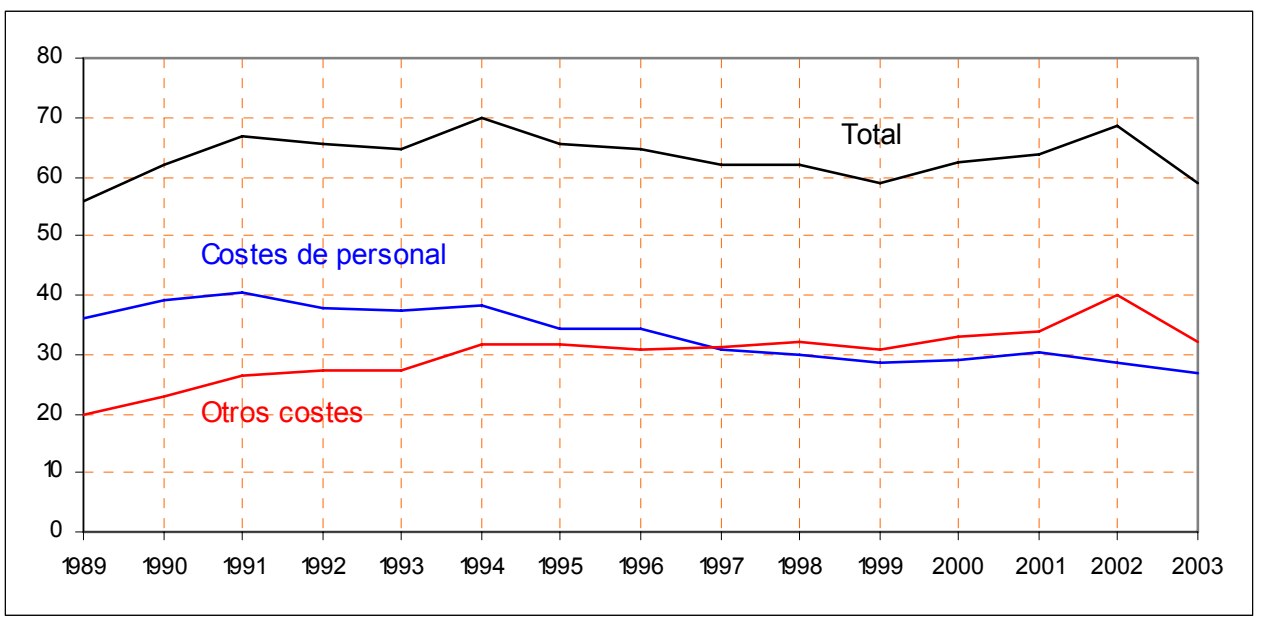

Fuente: Estadística Minera de España.

\section{UNA PROFUNDA TRANSFORMACIÓN DE LA ESTRUCTURA}

\section{EMPRESARIAL}

Los efectos de la reestructuración en el censo empresarial han resultado también sobresalientes: en 2005 , sólo mantenían su actividad once compañías, una contracción del 87 por 100 -similar a la que tuvo lugar a escala nacional- que fue el resultado del cierre de 46 compañías y de la absorción de otras 28.

Ambos procesos han resultado de gran trascendencia, tanto por el número de empresas afectadas como por su peso en la industria. Así, los productores que han ido abandonando la actividad desde 1989 daban empleo ese año a 3.590 trabajadores, y suministraban un total de 1,37 millones de toneladas de carbón subterráneo (Tabla 2). Es decir, representaban, aproximadamente, el 30 por 100 de la minería de la provincia. La mayor parte de ellos se retiró del negocio en la primera mitad de los noventa ${ }^{4}$.

$4 \quad$ Existen algunos casos importantes en los que el abandono se produjo después de 1995. Minas Leonesas de Espina fue declarada en quiebra en 1996. Antracitas de Matarrosa cerró en 1997: «El Delegado Regional de Trabajo, Francisco Javier Otazu, ha presidido el acuerdo entre la dirección de esta empresa y los representantes de los trabajadores, para el cierre definitivo de esta explotación minera, ubicada en el bierzo leonés. El agotamiento del yacimiento y las dificultades económicas de la empresa han sido las causas que han ocasionado el cierre de esta explotación, que contaba con una plantilla de 84 trabajadores» (Expansión, 17 de febrero de 1997). 
Tabla 2. Productores leoneses de carbón que han cesado en su actividad desde 1990

\begin{tabular}{|l|l|c|c|}
\hline \multicolumn{1}{|c|}{ Empresa } & \multicolumn{1}{|c|}{ Cuenca } & $\begin{array}{c}\text { Plantilla } \\
\text { en 1989 }\end{array}$ & $\begin{array}{c}\text { Suministros } \\
\text { subterráneos } \\
\text { en 1989 (kt) }\end{array}$ \\
\hline Hulleras de Sabero & Sabero & 960 & 253 \\
\hline Antracitas del Bierzo & El Bierzo & 424 & 138 \\
\hline Combustibles de Fabero & El Bierzo & 333 & 137 \\
\hline Antracitas de Marrón & El Bierzo & 193 & 50 \\
\hline Minas Leonesas de Espina & El Bierzo & 190 & 51 \\
\hline Carbones San Antonio & El Bierzo & 160 & 48 \\
\hline Antracitas de Besande & Valderrueda & 132 & 55 \\
\hline Antracitas de Matarrosa & El Bierzo & 118 & 103 \\
\hline Carbones Montealegre & El Bierzo & 95 & 63 \\
\hline Mina Carmen & La Magdalena & 81 & 41 \\
\hline Minas de Valdesamario & El Bierzo & 77 & 27 \\
\hline Resto (35 empresas) & & 827 & 404 \\
\hline Totales & & $\mathbf{3 . 5 9 0}$ & $\mathbf{1 . 3 7 0}$ \\
\hline
\end{tabular}

Fuente: Actas de la Comisión de Seguimiento del NSCCT, IRMC y Registro Mercantil.

El 72 por 100 de los cierres tuvo como escenario la cuenca berciana, donde 33 compañías salieron del mercado. No obstante, no ha sido ésta la zona más afectada por el proceso: en La Magdalena, la industria carbonera ha desaparecido por completo, y en las cuencas orientales las consecuencias de la reestructuración han sido, asimismo, contundentes. Precisamente, los efectos más negativos de la crisis minera se manifestaron en la cuenca de Sabero. Aquí, la desaparición de la actividad que había sido la base económica de la comarca durante un siglo transformó radicalmente el escenario del espacio geográfico, dejando sus posibilidades de desarrollo a merced de algo que llevaba mucho tiempo sin ponerse a prueba: la capacidad de adaptación del territorio a un cambio sustancial de su estructura productiva. Desde el punto de vista del desarrollo, el abandono de la minería en Sabero y el subsiguiente proceso de reindustrialización constituyen dos de los fenómenos más significativos que han acontecido en las cuencas mineras leonesas en los tres últimos lustros.

Pero, como apuntábamos al comenzar este apartado, la estructura actual de la minería leonesa no es sólo el resultado de los cierres de unidades productivas. También han desempeñado un papel capital los incesantes cambios en el control de las compañías.

La relevancia de los procesos de fusión queda patente si consideramos que, aunque el tamaño de las absorbidas era muy diverso, en conjunto contaban en 1989 con una plantilla de 3.197 trabajadores, y 
suministraban 1,3 millones de toneladas de carbón subterráneo (Tabla 3), lo cual significa que suponían en torno a la cuarta parte de la industria carbonera provincial. Estamos, pues, en presencia de una profunda transformación de la estructura empresarial, ocasionada, además de por el abandono de la actividad, por cambios trascendentales en la propiedad de las explotaciones. Ante esta circunstancia, aparte de averiguar qué unidades han desistido y cuáles permanecen activas, debemos intentar comprender quién se ha hecho finalmente con el control del sector.

Tabla 3. Productores leoneses de carbón activos en 1990 que fueron absorbidos hasta el 31 de diciembre de 2005

\begin{tabular}{|c|c|c|c|}
\hline Empresa & Cuenca & $\begin{array}{c}\text { Plantilla } \\
\text { en } 1989\end{array}$ & $\begin{array}{l}\text { Suministros } \\
\text { subterráneos } \\
\text { en } 1989 \text { (kt) }\end{array}$ \\
\hline Antracitas Gaiztarro & El Bierzo & 866 & 400 \\
\hline Antracitas de Fabero & El Bierzo & 463 & 108 \\
\hline Antracitas de Brañuelas & El Bierzo & 286 & 52 \\
\hline Viloria Hermanos & El Bierzo & 200 & 83 \\
\hline Minas y Explotaciones Industriales & El Bierzo & 191 & 63 \\
\hline Coto Minero del Sil (Victoriano Glez.) & El Bierzo & 164 & 72 \\
\hline Antracitas del Salgueiro & El Bierzo & 106 & 47 \\
\hline Minas de Ventana & San Emiliano & 102 & 36 \\
\hline Carbonia & Cármenes-Villamanín & 101 & 51 \\
\hline Antracitas La Silva & El Bierzo & 86 & 22 \\
\hline Antracitas de La Granja & El Bierzo & 83 & 51 \\
\hline Minera Peñarrosas & El Bierzo & 74 & 46 \\
\hline Minera de Fontoria & El Bierzo & 58 & 28 \\
\hline Mina Adelina & El Bierzo & 44 & 17 \\
\hline Malaba & El Bierzo & 43 & 28 \\
\hline Minas de Navaleo & El Bierzo & 43 & 27 \\
\hline Minera de Torre & El Bierzo & 34 & 14 \\
\hline Mina Mora $1 .^{\mathrm{a}}$ Bis & Villablino & 33 & 25 \\
\hline Grupo Minero El Porvenir & El Bierzo & 31 & 16 \\
\hline Minas de Sorbeda & El Bierzo & 31 & 17 \\
\hline Antracitas de Arlanza & El Bierzo & 28 & 15 \\
\hline Mina Goya & El Bierzo & 25 & 13 \\
\hline Minas de Lumajo & Villablino & 22 & 12 \\
\hline Carbones El Túnel & El Bierzo & 22 & 11 \\
\hline Mina Emilio & El Bierzo & 21 & 19 \\
\hline Mina Los Compadres & El Bierzo & 20 & 7 \\
\hline Sociedad Santa Bárbara & Villablino & 11 & 4 \\
\hline Explotaciones Mineras de Caboalles & El Bierzo & 9 & 10 \\
\hline \multicolumn{2}{|l|}{ Totales } & 3.197 & 1.294 \\
\hline
\end{tabular}

Fuente: Actas de la Comisión de Seguimiento del NSCCT, IRMC y BORME. 
Al comenzar la década de los noventa, se perfilaban claramente en Castilla y León los tres grupos empresariales que estaban llamados a convertirse en los protagonistas de la evolución de la industria carbonera regional (Figura 5). Aun cuando los tres afrontaban problemas comunes en el incierto panorama abierto por el Plan de Reordenación, resultaban patentes las diferencias entre ellos, tanto en lo que se refiere a la cultura organizacional como en lo relativo a las estrategias diseñadas. Así, mientras uno de ellos, la Vasco-Leonesa, concentraba todas sus energías en el ambicioso proyecto de la Nueva Mina, los otros dos continuaban extendiendo su influencia a diversas compañías carboneras.

Figura 5. Grupos empresariales más significativos de la industria carbonera leonesa en 1993

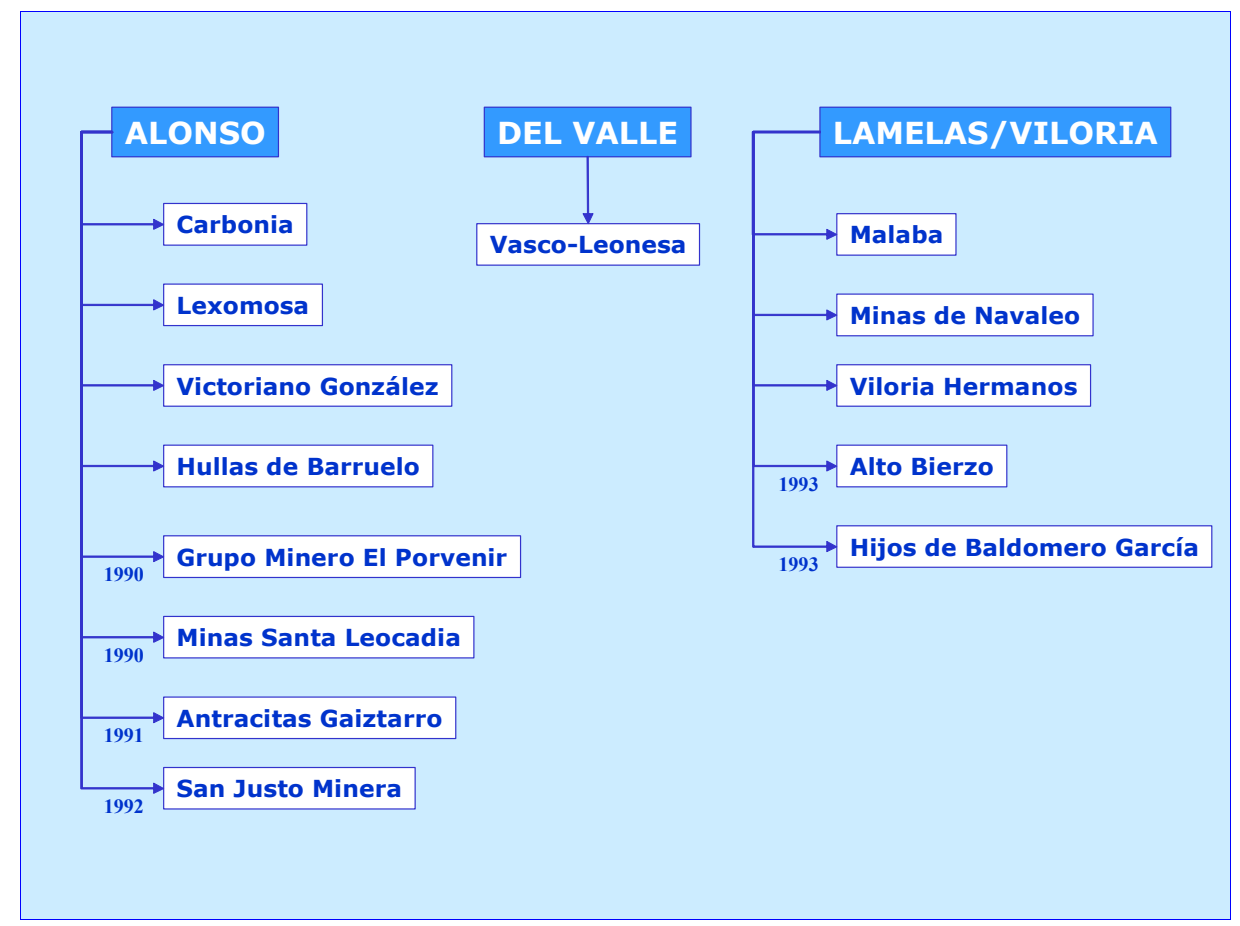

Fuente: Registro Mercantil.

En 1993, el grupo Lamelas/Viloria (que ya controlaba Malaba, Minas de Navaleo y Viloria Hermanos) copaba todos los puestos del consejo de administración de Hijos de Baldomero García, y se hacía con el control de Alto Bierzo.

Más notables fueron los movimientos de Victorino Alonso, cuyo influjo se extendía sin reparar en límites comarcales o provinciales. 
En 1993 tenía bajo su control a cuatro empresas bercianas (Grupo Minero El Porvenir, Minas Santa Leocadia, Antracitas Gaiztarro y Victoriano González), una palentina (Hullas de Barruelo) y una asturiana (San Justo Minera). Este elenco de empresas venía a sumarse a las dos que ya formaban parte de su naciente emporio a finales de los ochenta: Carbonia y Lexomosa.

Entretanto, la situación del principal productor de la región, MSP, empeoraba de forma alarmante. El 1 de enero de 1991, su importante explotación de La Camocha (Asturias), que en 1990 contaba con 1.242 trabajadores y extraía 280.000 toneladas, se convirtió de hecho en una empresa independiente, si bien la formalización legal de la operación no se llevaría a cabo hasta el mes de mayo de 1992. Con esta escisión, la plantilla de la firma lacianiega se situó en torno a los 2.700 efectivos; y su producción, en algo menos de 1,2 millones de toneladas ${ }^{5}$.

Obviamente, al exhibir La Camocha unos rendimientos tan bajos como los que se deducen de las cifras anteriores, la separación no pudo ser la causa de las graves dificultades económicas de MSP. En definitiva, fue la propia compañía quien solicitó la segregación, incapaz de frenar las pérdidas de sus grupos asturianos, compensadas desde 1982 por la Administración a través de la fórmula del contrato-programa.

Las raíces de la profunda crisis del productor de Villablino hay que buscarlas en las propias características de la industria nacional del carbón. Unas características agravadas, en el caso de MSP, por la contracción del laboreo a cielo abierto que siguió a la aplicación del NSCCT, los bajos rendimientos, la elevada conflictividad laboral y el recurso al endeudamiento con el que la compañía trató de compensar los efectos de unas pérdidas que se habían convertido en una constante desde 1983. En 1992, con unas deudas de más de 32.000 millones de pesetas que generaban unos gastos financieros de casi 3.000 millones, los resultados negativos -espoleados por la huelga que paralizó su actividad durante dos meses y que contrajo la producción hasta las 860.000 toneladas- alcanzaron 5.800 millones de pesetas. La sociedad, con unos recursos propios negativos de 468 millones de pesetas, se encontraba en quiebra técnica. La quiebra fue declarada el 2 de julio de 1993. 
Pero, como afirma Vega (2003: 282), la disolución de la empresa no le interesaba a nadie, ni a los trabajadores, ni a los acreedores, ni a las Administraciones Públicas. Éstas, sopesando el volumen de empleo de la compañía y el hecho de que desplegara su actividad en una zona deprimida, ya habían comprometido unos meses antes de la declaración de la quiebra sustanciosas ayudas para reflotarla ( 9.460 millones de pesetas la Administración central y 4.500 millones la Junta de Castilla y León). Se decidió, pues, que la quiebra fuese con continuidad, es decir, que no implicara la liquidación de la sociedad ni la interrupción de su actividad.

La estructura empresarial de la industria carbonera leonesa experimentó también cambios notables durante la segunda fase de la reestructuración. Entre 1994 y 1997, los dos acontecimientos más destacados fueron la entrada en funcionamiento de la Nueva Mina, que afianzó a la Vasco-Leonesa en los primeros lugares en cuanto a eficiencia se refiere, y la política expansiva que el grupo Alonso continuó desplegando.

Figura 6. El grupo Alonso en 1997

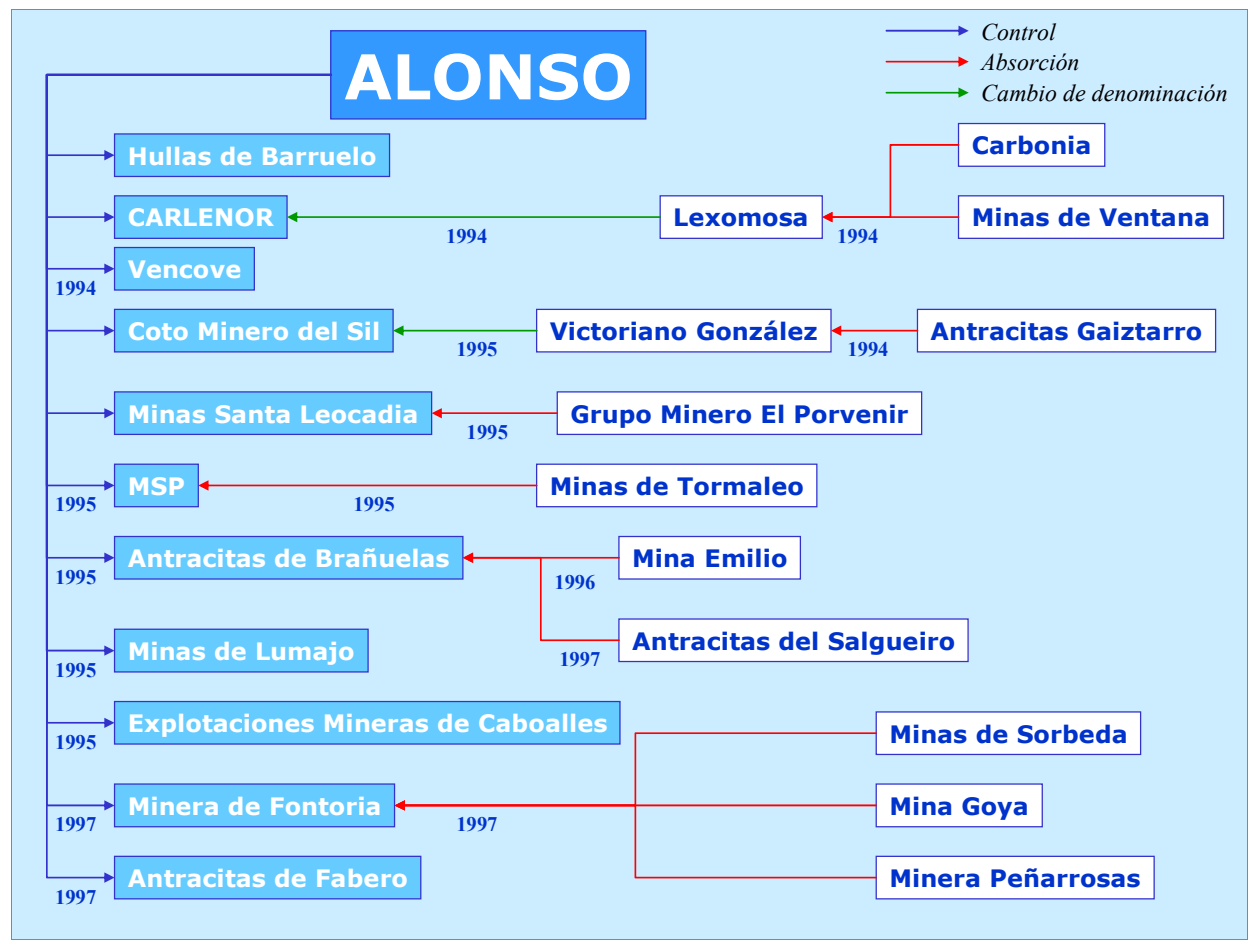

Fuente: Registro Mercantil. 
Intensificando la línea de actuación de años anteriores, las nuevas adquisiciones y fusiones incrementaron considerablemente el tamaño del conglomerado empresarial controlado por Alonso, y fueron una de las causas de la disminución del censo de compañías carboneras leonesas. La Figura 6 tiene como objetivo facilitar el seguimiento de las operaciones societarias planificadas por este empresario entre 1994 y 1997.

La primera tuvo como escenario las cuencas orientales leonesas: el 15 de junio de 1994 se fusionaron Carbonia, Minas de Ventana y Lexomosa, mediante la disolución de las dos primeras y su absorción por la tercera. Diez días después, su razón social pasó a ser Carbones León Norte, S.A. (CARLENOR).

Tres meses más tarde, otras dos compañías controladas por Alonso se fusionaron: Victoriano González absorbió a Antracitas Gaiztarro. En abril del año siguiente, la primera, convertida con diferencia en la principal empresa minera de la cuenca de Fabero y de todo el Bierzo, cambió su denominación por la de Coto Minero del Sil.

Pero la operación más significativa fue la adquisición en 1995 del 68 por 100 del capital de MSP (compañía que unos meses antes había absorbido a la asturiana Minas de Tormaleo $\left.{ }^{6}\right)$. La compra se realizó a través de las sociedades Comile $(35,88$ por 100$)$, Rioscalsa $(15,47$ por $100)$ y Universal Beximport (16,68 por 100$)$, las tres controladas por Alonso. La compra de las participaciones concluyó en junio; si bien la toma de posiciones del grupo en la empresa lacianiega fue anterior, pues ya en el mes de enero Victorino Alonso Suárez ocupaba el cargo de presidente, y en febrero su hijo era nombrado vicepresidente y consejero delegado.

La entrada de Alonso en MSP se produjo a raíz de la aprobación definitiva del convenio de acreedores el 1 de junio de 1994. Los principales acuerdos alcanzados por la junta de acreedores dieron lugar a las operaciones siguientes:

- Una rebaja de las deudas de un 75 por 100, que, de esta forma, pasaron de 34.413 millones de pesetas a 8.571 millones. El capital también se redujo por disminución del valor nominal de las acciones, quedando en 670 millones de pesetas.

6 En marzo de 1995, MSP lanzó una OPA por la totalidad de Minas de Tormaleo, sociedad de la que ya poseía el 32,87 por 100. La operación elevó esta participación por encima del 98 por 100, y culminó, en el mes de diciembre, con la fusión. La escritura de fusión por absorción se otorgó el 26 de diciembre de 1995 y fue inscrita en el Registro Mercantil de León el 7 de marzo de 1996. 
- La capitalización de las cantidades adeudadas a Caja España (504 millones de pesetas) y el Banco Exterior (530 millones de pesetas). La deuda se aminoró, por tanto, en otros 1.034 millones de pesetas, pasando de 8.571 millones a 7.537 millones de pesetas. En noviembre de 1994 se otorgó la escritura de ampliación de capital. Caja España mantuvo su participación (30 por 100); por el contrario, el Banco Exterior vendió sus acciones (31 por 100) a Universal Beximport y Rioscalsa. No ha sido posible averiguar la fecha exacta de esta operación, que es precisamente el momento en que Alonso comienza a controlar MSP, pero debió de acontecer a finales de 1994.

- La concesión de un plazo de siete años para el pago de la deuda pendiente tras la ampliación (7.537 millones de pesetas).

- Una ampliación de capital por valor de 2.000 millones de pesetas. La operación se efectuó el 8 de junio de 1995. El 65,18 por 100 de los títulos los suscribió Comile; el 17,22 por 100, Universal Beximport, y el 15,97 por 100, Rioscalsa. El grupo Alonso obtuvo, por tanto, el 98,37 por 100 de las nuevas acciones, cuyo importe $(1.976,346$ millones de pesetas), sumado al de los títulos que ya poseía (530 millones), representaba el 67,42 por 100 del capital de MSP ${ }^{7}$.

Además, Alonso se hizo con el control de tres compañías más en la cuenca de Villablino (Minas de Lumajo, Antracitas de Lumajo y Explotaciones Mineras de Caboalles), y siete en el Bierzo (Vencove, Antracitas de Brañuelas, Mina Emilio, Minas de Sorbeda, Antracitas del Salgueiro, Minera de Fontoria y Antracitas de Fabero). El prominente grupo carbonero controlaba así toda la cuenca de Fabero, por más que para ello hubiera tenido que adquirir una empresa con desequilibrios económicos tan graves como Antracitas de Fabero, cuya insolvencia definitiva había sido decretada por el Juzgado de Primera Instancia número 58 de Madrid, al ser su pasivo superior a su activo en 1.500 millones de pesetas.

A partir de 1998, los continuos cambios que acontecieron en la industria leonesa del carbón tuvieron nuevamente su causa fundamental en la expansión del grupo Alonso. En efecto, a lo largo de la tercera fase de la reordenación carbonera el proceso de concentración, lejos de detenerse,

La pequeña ampliación de capital efectuada como consecuencia de la adquisición de Tormaleo (12.255.750 pesetas) elevó la participación de Alonso hasta el 68,03 por 100. 
continuó su marcha y convirtió a este conglomerado empresarial en el principal productor de carbón del país (Figura 7).

Figura 7. La expansión de UMINSA

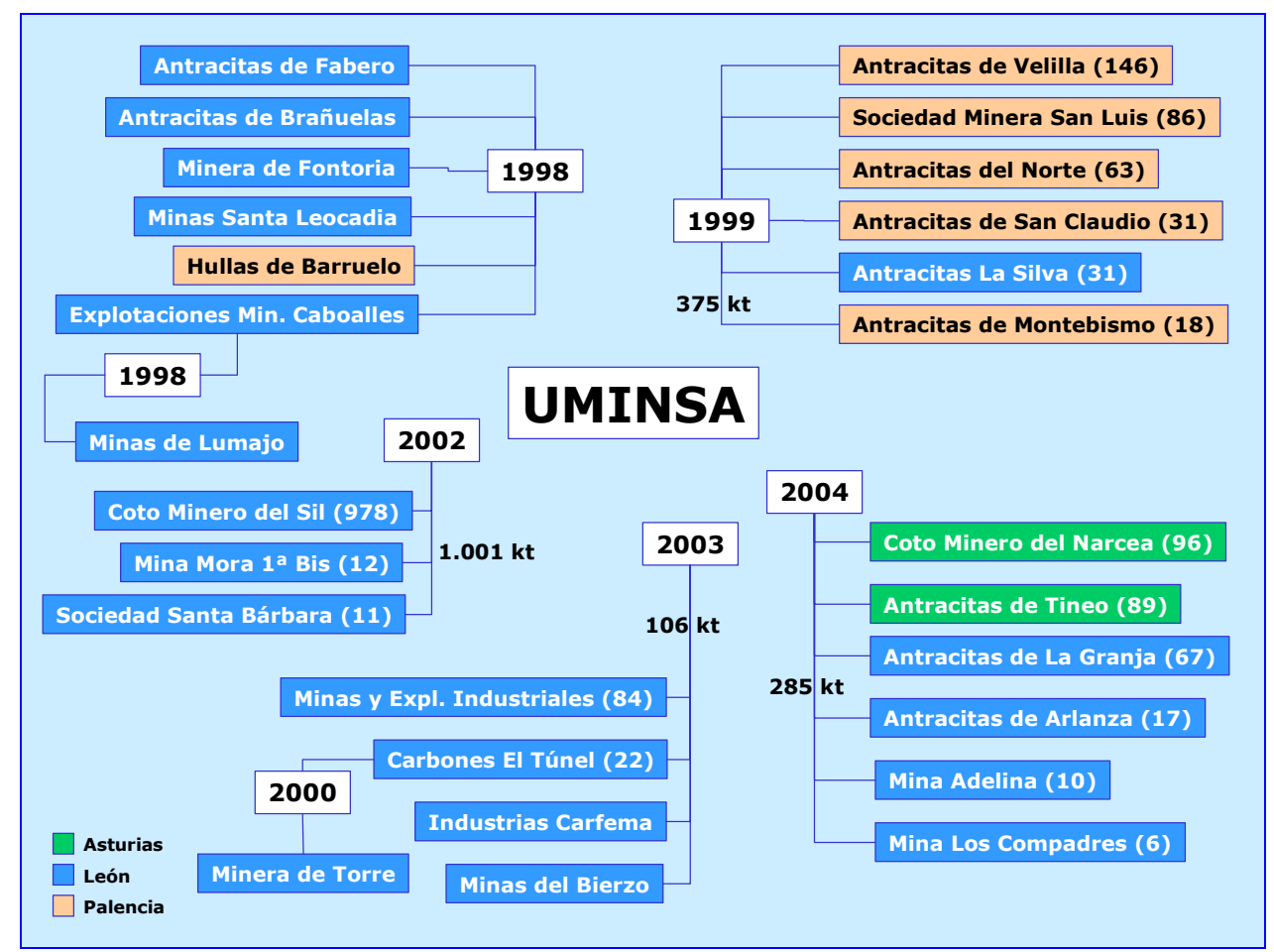

Fuente: Registro Mercantil.

En marzo de 1998, CARLENOR cambió su denominación por la de Unión Minera del Norte, S. A. (UMINSA), sociedad que absorbió en julio a seis compañías pertenecientes al grupo: Antracitas de Fabero, Antracitas de Brañuelas, Minera de Fontoria, Explotaciones Mineras de Caboalles (que previamente había absorbido a Minas de Lumajo), Minas Santa Leocadia y Hullas de Barruelo.

En 1999, Victorino Alonso compró Campomanes Hermanos (compañía que se hallaba al borde de la quiebra al no poder hacer frente a una deuda de 7,21 millones de euros con la Seguridad Social ${ }^{8}$ ) y todas las sociedades mineras palentinas con excepción de Carbones San Isidro y

$8 \quad$ La Voz de Galicia, 13 de abril de 1999. 
María9, es decir, pasaron a integrarse en el grupo: Antracitas de Velilla, Sociedad Minera San Luis, Antracitas del Norte, Antracitas de San Claudio y Antracitas de Montebismo ${ }^{10}$. Estas cinco compañías, más Antracitas La Silva, serían absorbidas por UMINSA ese mismo año.

También en 1999, el grupo Alonso pasó a dominar a la sociedad Mina Mora $1 .^{\mathrm{a}}$ Bis, que inmediatamente después solicitó la declaración de suspensión de pagos (la declaración tuvo lugar en noviembre de 2000). En 2000 fue la Sociedad Santa Bárbara la que cayó en la órbita del grupo minero. En 2002, UMINSA absorbió a las dos compañías anteriores y a Coto Minero del Sil, sociedad de la que era único accionista, y que había sido declarada en suspensión de pagos en mayo de 2000. En 2003 corrieron igual suerte Minas y Explotaciones Industriales, Carbones El Túnel, Industrias Carfema y Minas del Bierzo. La segunda de las sociedades mencionadas había absorbido en 2000 a Minera de Torre.

La toma de posiciones en otras compañías continuaba sin tregua. El control de Virgilio Riesco tuvo lugar en 2003, año en el que se produjo la adquisición de Mina Adelina, Mina Los Compadres y Coto Minero del Narcea. En los primeros meses de 2004, tres empresas más se integraban en el emporio de Victorino Alonso: Antracitas de La Granja, Antracitas de Arlanza y Antracitas de Tineo. Siguiendo el mismo procedimiento que en ocasiones anteriores, en mayo de 2004 las juntas generales extraordinarias y universales de UMINSA, Mina Adelina, Mina Los Compadres, Antracitas de La Granja, Antracitas de Arlanza, Antracitas de Tineo y Coto Minero del Narcea aprobaron por unanimidad la fusión por absorción de las últimas por parte de la primera ${ }^{11}$.

En 2003 y 2004 también tuvieron lugar cambios decisivos en el accionariado de MSP que incrementaron el control de Victorino Alonso sobre la entidad. En 2003, el Juzgado de Madrid que llevaba el proceso declaró extinguida la quiebra de la compañía. Poco después, Caja España vendió sus acciones $(13,561$ por 100$)$ a Victorino Alonso, pese a lo cual la

9 El País, 20 de enero de 1999, y El Norte de Castilla, 2 de abril de 1999.

10 El 30 de julio de 2005, UMINSA cerró el grupo Peragido de Barruelo de Santullán y trasladó a los 40 mineros que trabajaban en él al grupo El Abuelo, situado en Velilla del Río Carrión, el único pozo que permanece activo en la provincia de Palencia (Diario de León, 1 de agosto de 2005).

11 Expansión, 26 de mayo de 2004. 
entidad financiera logró mantener, de forma testimonial, un representante en el consejo de administración ${ }^{12}$.

El 2 de enero de 2004, MSP lanzó una OPA sobre el 30 por 100 de sus propias acciones para proceder a la reducción del capital social mediante la amortización de los títulos adquiridos. Dos meses después, cuando finalizó la operación, los 1.473 accionistas que la habían aceptado representaban aproximadamente el 15 por 100 del capital de la sociedad $^{13}$. Una vez amortizadas las acciones adquiridas, el grupo Alonso pasó a controlar el 86 por 100 de MSP. Unos meses después, la junta general extraordinaria de accionistas celebrada el día 27 de octubre de 2004 adoptó, con los votos favorables del 87,58 por 100 del capital social, solicitar a la Comisión Nacional del Mercado de Valores la exclusión de negociación en la Bolsa de Valores de Madrid de todas las acciones de MSP, acontecimiento que tuvo lugar en octubre de 2005.

El último episodio en la historia expansiva del grupo Alonso comenzó en diciembre de 2005 con el lanzamiento de una OPA sobre la empresa asturiana Hullas del Coto Cortés, una operación valorada positivamente por el Banco Pastor, que controlaba el 63 por 100 del capital de esta entidad y cuya estrategia pasaba por deshacerse de buena parte de sus participaciones industriales para centrarse en el negocio bancario $^{14}$. La operación concluyó en mayo de 2006 con la adquisición del 75 por 100 de las acciones (2,681 millones de títulos), lo que supondrá un desembolso de 28,7 millones de euros ${ }^{15}$.

Como consecuencia de las operaciones llevadas a cabo, la sección carbonera del grupo empresarial controlado por Victorino Alonso estaba formada en 2005 por cuatro compañías (Figura 8): MSP, Campomanes Hermanos, Virgilio Riesco y UMINSA. Desde 1998, esta última había absorbido directamente a 25 sociedades leonesas, palentinas y asturianas. Campomanes Hermanos y Virgilio Riesco se mantienen fuera de UMINSA

12 Diario de León, 28 de diciembre de 2003.

13 En total la compañía compró 23.310.230 acciones, que representaban el 15,6 por 100 de su capital (cuentas anuales de MSP).

14 La oferta era por el 100 por 100 de las acciones (3.575.000 títulos) y el precio ofrecido asciende a 10,7 euros, lo que coloca el montante de la operación en 38,3 millones de euros.

15 Diario de León, 20 de mayo de 2006. 
por los convenios de acreedores que están afrontando tras superar la situación de suspensión de pagos ${ }^{16}$.

Figura 8. El grupo Alonso en 2005

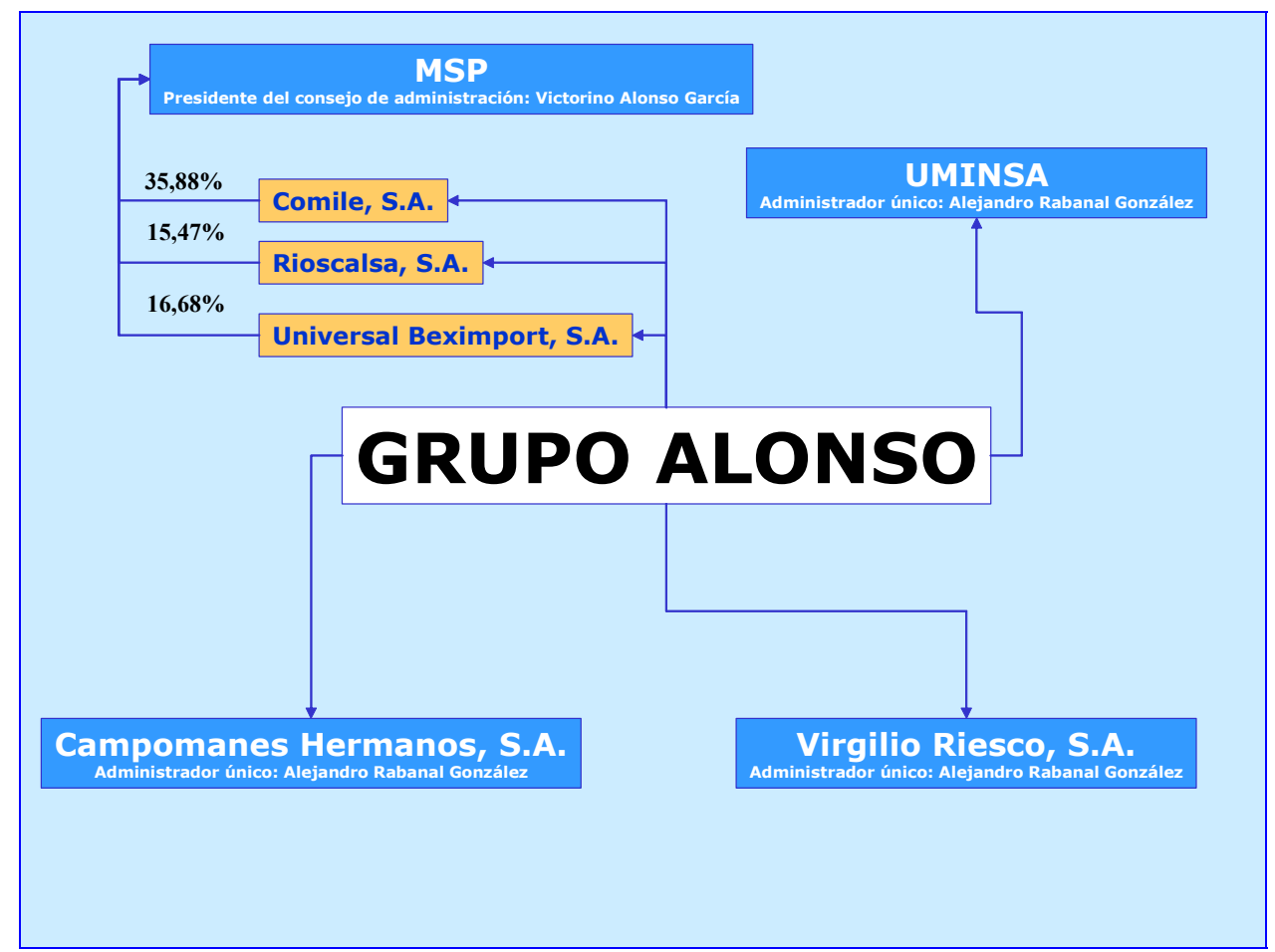

Fuente: Registro Mercantil y cuentas anuales.

En 2005, el carbón extraído en León (Figura 9) procedió del grupo Alonso, la Vasco-Leonesa, el grupo Lamelas/Viloria y un grupo de pequeños productores independientes (Carbones Arlanza, Carbones del Puerto, Mina La Sierra y Minas de Valdeloso). Las cuatro sociedades del grupo Lamelas/Viloria que operan en Torre del Bierzo se fusionaron a finales de 2004 (Alto Bierzo absorbió a Malaba, Viloria Hermanos y Minas de Navaleo). Por tanto, al finalizar 2005 quedaban en la provincia once empresas carboneras, tres de las cuales (Virgilio Riesco, Mina La Sierra y Minas de Valdeloso) se encuentran incluidas en el Plan de Cierre.

16 Diario de León, 28 de abril de 2004. 
Figura 9. Estructura empresarial de la minería leonesa en 2005

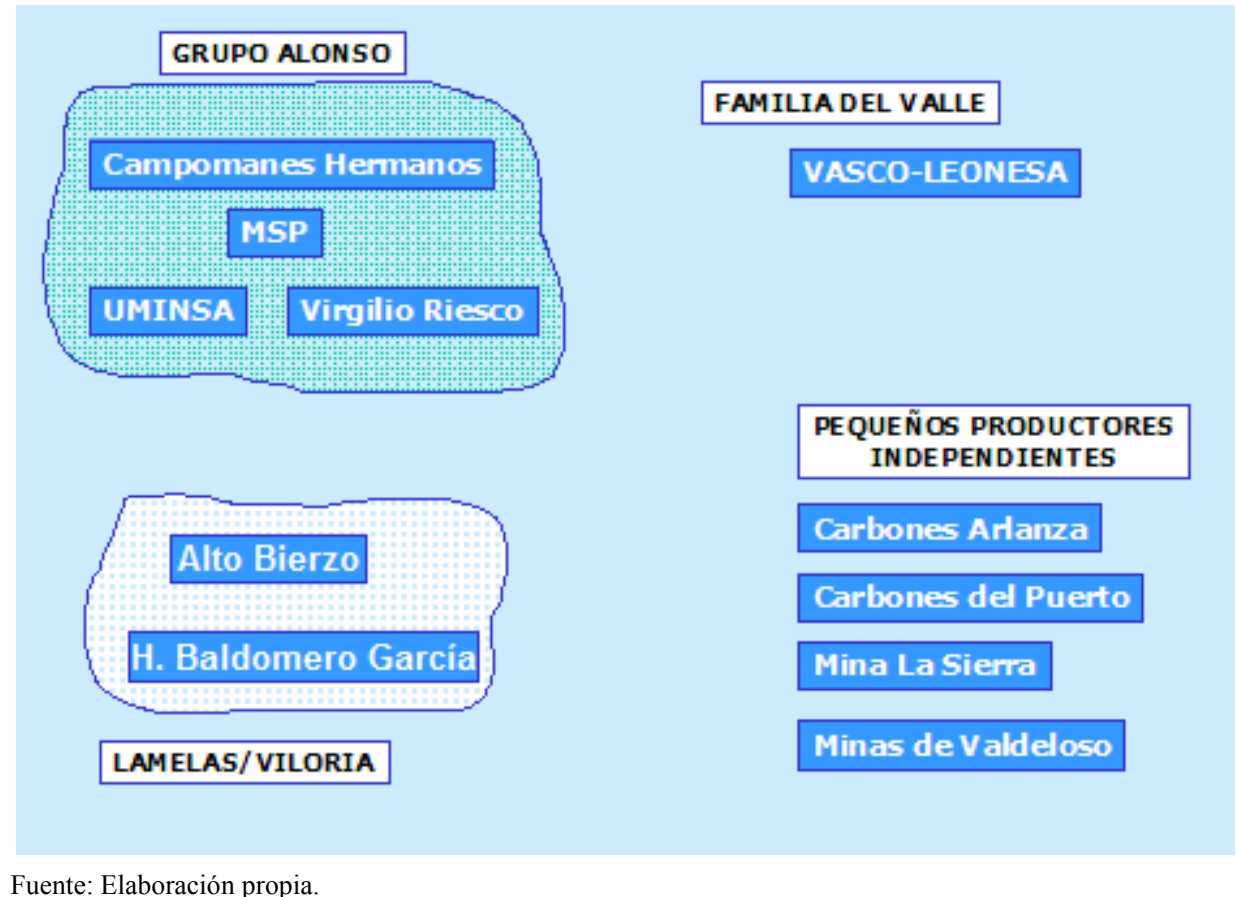

La importancia de los diferentes grupos empresariales en la producción regional se muestra en la Tabla 4 . Los pesos de los tres más significativos, muy desiguales entre sí, han crecido en los últimos años a expensas de los pequeños productores.

Tabla 4. Grandes grupos empresariales de la industria carbonera en Castilla y León (toneladas contratadas), 1998 y 2004

\begin{tabular}{|l|r|r|r|r|r|}
\hline \multirow{2}{*}{} & \multicolumn{2}{|c|}{$\mathbf{1 9 9 8}$} & \multicolumn{2}{c|}{$\mathbf{2 0 0 4}$} \\
\hline Grupo Alonso & \multicolumn{1}{|c|}{ kt } & \multicolumn{1}{c|}{$\%$} & \multicolumn{1}{c|}{$\%$} \\
\hline Vasco-Leonesa & 1.265 & 63,0 & 3.384 & 67,3 \\
\hline Grupo Lamelas-Viloria & 383 & 18,4 & 1.195 & 23,8 \\
\hline Resto & 894 & 5,6 & 378 & 7,5 \\
\hline Totales & $\mathbf{6 . 8 7 8}$ & 13,0 & 74 & 1,5 \\
\hline
\end{tabular}

Fuente: IRMC. 
El notable descenso, en términos absolutos, de las toneladas contratadas por las compañías del grupo Alonso tiene su causa en la política de cierre de explotaciones llevada a cabo por este empresario. Los más significativos tuvieron lugar en 2000. Ese año cerraron los grupos que UMINSA mantenía en la Montaña Centro-Oriental (Picalín, Pontedo y Arbás) y el grupo María de MSP. El cierre de este último, que contaba con 122 trabajadores, se llevó a cabo el 27 de septiembre, pero ya el 4 de febrero, debido a un grave incidente, se habían suspendido todas las labores de arranque. Previamente habían cerrado el grupo Carrasconte y el denominado Sector Mina del Río del grupo Paulina. En 2004 cesó la actividad del grupo Lumajo, causa principal de las pérdidas de MSP ese año.

Lógicamente, el grado de concentración de la industria carbonera de Castilla y León ha experimentado un considerable aumento ${ }^{17}$ : utilizando como indicador las toneladas contratadas, el índice de HirschmanHerfindahl ha crecido un 76 por 100 desde $1998^{18}$. No obstante, si tenemos en cuenta la existencia de estrechas relaciones entre algunos productores, deberemos concluir que el porcentaje anterior no refleja del todo la realidad. Considerando esta circunstancia, el incremento del grado de concentración ha sido sólo de un 18 por 100, pero ha alcanzado en 2004 cotas superiores a las de una industria formada por dos únicas empresas de igual tamaño ${ }^{19}$.

En el conjunto de la industria nacional de la hulla y la antracita, las empresas leonesas copan en la actualidad los primeros puestos en la clasificación que atiende a la capacidad extractiva. El primero lo ocupa UMINSA (26 por 100); el tercero, la Vasco-Leonesa (14 por 100); y el cuarto, MSP (11 por 100). La participación del conglomerado de empresas de Victorino Alonso, con una capacidad de producción de 3,2 millones de toneladas, se acerca ya al 40 por 100 .

17 Al contar UMINSA con explotaciones en León y Palencia, no se ha podido referir el análisis únicamente a la minería leonesa. Las conclusiones, no obstante, se pueden aplicar a la provincia de León, dada la escasa entidad de la industria carbonera palentina.

18 En 1998 era igual a 0,1696, y en 2004 a 0,298337.

19 Considerando las relaciones de dominio, el grado de concentración ascendía a 0,435217 en 1998, y a 0,515262 en 2004 


\section{DE LA MINERÍA LEONESA}

\section{EL EFECTO DE LA REESTRUCTURACIÓN SOBRE LA VIABILIDAD}

En última instancia el objetivo de cualquier proceso de reestructuración es conseguir que las unidades productivas que se mantengan activas sean viables, es decir, que puedan competir sin necesidad de ayudas públicas. Por tanto, para finalizar debemos preguntarnos en qué medida dicho objetivo se ha conseguido en el caso de las minas leonesas.

En la Figura 10 se han representado la evolución del precio internacional y de los costes de producción medios nacionales y leoneses. La conclusión más relevante es, obviamente, que la minería leonesa es inviable. No obstante, lo es en menor medida que la industria nacional. En efecto, las dos series de costes experimentan las mismas oscilaciones y se sitúan sistemáticamente muy por encima del precio internacional, pero el coste leonés es aproximadamente un 24 por 100 menor que el nacional.

Figura 10. Evolución del precio internacional y de los costes de producción en la minería nacional y leonesa (dólares/tonelada), 1989-2003

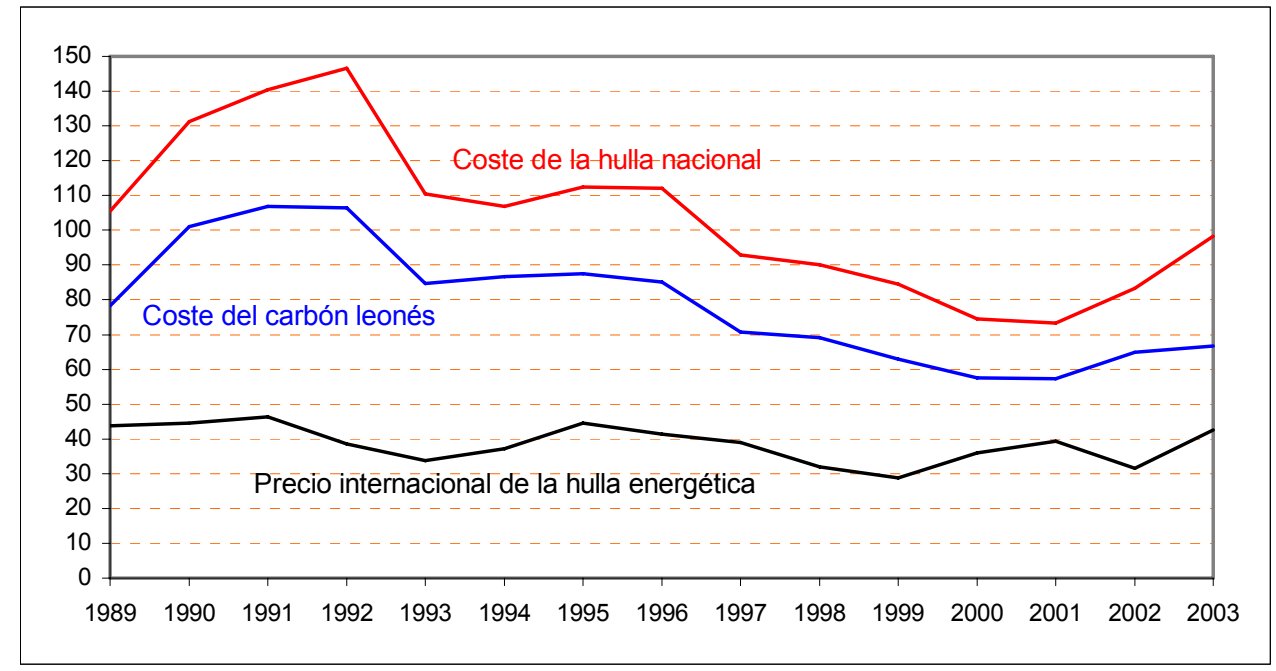

Fuente: IGME, Estadística Minera de España, IRMC y Banco de España.

De este modo, el coste de las minas leonesas en 2003 era sólo un 57 por 100 mayor que el precio internacional. Si tenemos en cuenta que en 1992 había llegado a ser un 176 por 100 más elevado, el progreso conseguido en la última década es evidente. Esta positiva evolución, por más que tenga su causa principal en la evolución de los tipos de cambio, ha 
permitido que, según los datos de la Estadística Minera de España, el coste de producción leonés no alcance los 70 dólares/tonelada desde 1999.

A la vista de las recientes subidas experimentadas por la cotización internacional de la hulla energética (que se aproximó a 79 dólares en diciembre de 2004), surge el interrogante de si la viabilidad de las minas leonesas ha dejado de ser una meta inalcanzable. Dejando a un lado la cuestión de la calidad del carbón, la respuesta sería positiva si la Estadística Minera de España reflejara fielmente la estructura de costes de la industria, pero lamentablemente esto no es así.

En 2003, UMINSA, MSP y la Vasco-Leonesa extraían el 84 por 100 del carbón leonés. Sus costes unitarios de producción ascendían a 77, 87 y 82 euros, respectivamente. Si los expresamos en dólares obtenemos 87 , 98 y 93, frente al coste medio de 67 dólares que se deduce de la Estadística Minera de España. A partir de estas cifras, podemos estimar que el coste medio real de las minas de la provincia rondaba los 81 euros (92 dólares), y que resultaba ser un 37 por 100 más alto que el obtenido con los datos de la estadística oficial. Lo fundamental es que el coste real del carbón leonés duplicaba en 2003 holgadamente la cotización internacional de la hulla térmica, y que la industria provincial se encontraba muy lejos de la viabilidad, pese a ser más eficiente que cuando se inició la reestructuración.

Llegados a este punto, resulta inevitable que nos preguntemos por los motivos que guían la política expansiva de los principales productores leoneses. La compra de unidades productivas, muchas de ellas en situación crítica, en una industria en reestructuración y con insalvables problemas de viabilidad carece, aparentemente, de cualquier lógica empresarial. No obstante, forzosamente debe poseer alguna.

La clave última se encuentra en la rentabilidad del negocio. Pese al monocorde discurso de la Comisión Europea, la política carbonera española garantiza sustanciosos beneficios a las empresas más eficientes del sector. Como refleja la Tabla 5, entre 1998 y 2004, MSP y UMINSA obtuvieron unos beneficios de 23 y 90 millones de euros, respectivamente ${ }^{20}$. Sin menospreciar el esfuerzo realizado por las dos compañías para mejorar su eficiencia, el elemento clave de estos resultados positivos residió en las ayudas para cubrir pérdidas de explotación, que ascendieron a 375 y 365

20 De los 90 millones de euros de beneficios de UMINSA, 21 corresponden a quitas de los convenios de acreedores de diversas sociedades absorbidas. 
millones de euros, el 49 y el 43 por 100 de todos los ingresos de explotación de MSP y UMINSA. Sin estas ayudas, las pérdidas habrían totalizado 348 millones en la primera compañía y 271 millones en la segunda (el gasto por el impuesto sobre sociedades supuso 4,1 y 2,8 millones, respectivamente), lo que representaría un resultado negativo medio de 50 y 39 millones de euros al año.

Tabla 5. Ingresos, ayudas al funcionamiento y resultados de MSP y UMINSA (miles de euros), 1998-2004

\begin{tabular}{|c|c|c|c|c|c|c|c|c|}
\hline & 1998 & 1999 & 2000 & 2001 & 2002 & 2003 & 2004 & Total \\
\hline \multicolumn{9}{|l|}{ MSP } \\
\hline Ingresos de explotación & 137.564 & 117.937 & 125.092 & 107.177 & 98.545 & 94.622 & 87.662 & 768.599 \\
\hline Ayudas al funcionamiento & 66.195 & 59.646 & 57.861 & 52.713 & 47.999 & 46.079 & 44.236 & 374.729 \\
\hline Resultados & 7.435 & 5.891 & 4.737 & 1.256 & 5.035 & 127 & -1.926 & 22.555 \\
\hline \multicolumn{9}{|l|}{ UMINSA } \\
\hline Ingresos de explotación & 58.906 & 94.266 & 107.666 & 95.903 & 166.459 & 158.352 & 171.775 & 853.327 \\
\hline Ayudas al funcionamiento & 33.134 & 37.944 & 42.367 & 40.786 & 69.801 & 67.836 & 73.038 & 364.906 \\
\hline Resultados & 9.114 & 13.363 & 16.747 & 16.870 & 24.939 & 193 & 9.222 & 90.448 \\
\hline
\end{tabular}

Fuente: Cuentas anuales.

La política carbonera nacional es, por tanto, el factor crucial en el que se basan las decisiones empresariales. En general, además, los empresarios confían en el mantenimiento en el tiempo de las ayudas y la protección. Las cuatro centrales térmicas de la región - lejos de la costa y diseñadas para quemar mineral autóctono-, los problemas de desarrollo de las comarcas mineras, y unos sindicatos muy combativos, son las mejores garantías de que la Administración e incluso las compañías eléctricas propietarias de las térmicas abogarán por la industria nacional del carbón. Por supuesto, en determinados momentos aumenta la incertidumbre sobre la continuidad de las ayudas (debido a cambios en la normativa comunitaria o a reclamaciones de la Comisión, por ejemplo), y entonces las inversiones mineras se retraen.

Sólo en ese marco es posible entender que la Vasco-Leonesa emprendiera su colosal proyecto, o que Victorino Alonso se lanzara desaforadamente a la adquisición de minas. En cierta forma, lo que este empresario compra no es tanto una explotación minera como el derecho a vender una determinada cantidad de mineral a un precio muy provechoso. Por otro lado, su participación creciente en la industria carbonera le confiere una ventaja nada despreciable a la hora de negociar con la 
Administración y las compañías eléctricas en aquellos casos en los que la evolución de los acontecimientos no sea la deseada.

Como avanzábamos al comenzar este apartado, la conclusión más significativa es que las minas leonesas, tras dos décadas de reordenación, siguen siendo inviables y dependen totalmente de las ayudas públicas para continuar con su actividad. Su delicada situación se ha complicado aún más con la entrada en vigor de las nuevas normas tendentes a moderar las emisiones contaminantes a la atmósfera. El cumplimiento de los compromisos internacionales de carácter ambiental asumidos por nuestro país tiene un considerable escollo en la quema de los combustibles fósiles utilizados para generar electricidad, y muy especialmente en el consumo de carbón autóctono. Las cuatro térmicas ubicadas en Castilla y León emiten cada año a la atmósfera más de 157.000 toneladas de dióxido de azufre, casi 87.000 de óxidos de nitrógeno y 16 millones de toneladas de dióxido de carbono. Para ellas, por tanto, revisten una importancia capital tanto las directrices del Plan Nacional de Reducción de Emisiones de las Grandes Instalaciones de Combustión Existentes como las del Plan Nacional de Asignación de Derechos de Emisión. Algo que también resulta fundamental para la industria extractiva leonesa, cuya continuidad depende totalmente de que las centrales térmicas ubicadas en la región mantengan su actividad.

Así pues, están lejos de despejarse las incógnitas sobre el futuro tanto de la industria carbonera leonesa como de los territorios que, pese a los tímidos atisbos de diversificación económica, siguen teniendo en ella el soporte fundamental de su estructura productiva.

\section{BIBLIOGRAFÍA}

Actas de la Comisión de Seguimiento del Nuevo Sistema de Contratación del Carbón Térmico.

Cuentas anuales de UMINSA y MSP.

Diario de León.

Documento sin fecha de la Comisión de Seguimiento del Nuevo Sistema de Contratación del Carbón Térmico donde figura el patrimonio neto, los resultados, las plantillas y los suministros subterráneos de las empresas carboneras en 1989. 
El Norte de Castilla.

El País.

ENTE Regional de LA EnergíA, Estadística Energética de Castilla y León.

Expansión.

IRMC (Instituto para la Reestructuración de la Minería del Carbón y el Desarrollo Alternativo de las Comarcas Mineras), datos internos.

La Voz de Galicia.

MINISTERIO DE INDUSTRIA, TURISMO Y COMERCIO, Estadística Minera de España.

Nuevo Sistema de Contratación del Carbón Térmico (convenio marco firmado por Unesa y Carbunión el 10 de diciembre de 1986).

Plan 1998-2005 de la Minería del Carbón y Desarrollo Alternativo de las Comarcas Mineras.

Plan Nacional de Reserva Estratégica de Carbón 2006-20012 y Nuevo Modelo de Desarrollo Integral y Sostenible de las Comarcas Mineras.

VEGA CRESPO, Josefa (2003) Minero Siderúrgica de Ponferrada 1918-2010. Historia y futuro de la minería leonesa. Madrid: LID Editorial Empresarial. 





\section{NORMAS DE PUBLICACIÓN}

Los artículos deben enviarse al Director de la Revista, Facultad de Ciencias Económicas y Empresariales, Universidad de León, Campus de Vegazana, 24071 León.

La Revista entiende que los trabajos son originales, es decir, no han sido publicados con anterioridad o no están en proceso de publicación en otro lugar.

especificaciones:

Los trabajos tendrán que ajustarse a las siguientes

- Mecanografiado a espacio sencillo por una sola cara y con márgenes de $3 \mathrm{~cm}$. superior e inferior, izquierda y derecha.

- La extensión recomendable para los artículos se sitúa entre 15 y 20 páginas, incluidos gráficos, cuadros y bibliografía.

- Las páginas se numerarán de forma consecutiva, correspondiendo la primera al título, autor/es del trabajo y su dirección de contacto. La segunda, al título, un resumen del trabajo y las palabras clave, tanto en español como en inglés, que deberá tener una extensión máxima de 200 palabras. Se deben especificar de 3 a 10 palabras clave que den una idea rápida del contenido del trabajo y faciliten su informatización.

- El texto del trabajo comenzará en la tercera página y las secciones se enumerarán consecutivamente. Todos los diagramas, gráficos, tablas, cuadros o figuras irán debidamente insertados en el texto.

- Las referencias bibliográficas se incluirán ordenadas alfabéticamente al final del trabajo, y de forma cronológica en el caso de varios trabajos del mismo autor. La citación completa se hará en el siguiente orden:

1. APELLIDO, Nombre del autor.

2. Fecha de publicación (entre paréntesis). 

3. Título completo del trabajo. En itálica cuando se trate de un libro y entre comillas si es un artículo.

4. En caso de ser una revista, nombre de la misma, en itálica, seguido del número de volumen, fascículo y primera y última páginas.

5. Finalmente, para los libros, figurará el lugar de la edición y la editorial.

- Las tablas y cuadros irán numerados consecutivamente con caracteres arábigos. Llevarán un encabezamiento conciso, similar al de las notas al pie, que explique los símbolos utilizados y permitan las aclaraciones necesarias.

- Se deberán enviar tres copias impresas del trabajo así como el archivo del mismo en Word 6.0 ó versión superior, bien en un diskette (3 $1 / 2$ alta densidad) o como fichero adjunto a un correo electrónico enviado a la dirección ulepec@unileon.es.

El Consejo de Redacción es el responsable final de la aceptación del trabajo, previo informe de los evaluadores, garantizando el anonimato tanto del autor como de los mismos.

La Dirección de la Revista acusará recibo de los originales $y$, recibido el parecer del Consejo Asesor, decidirá admitirlos en función de que respondan a la línea editorial de la misma y que cumplan las presentes normas.

Tras su admisión, los originales serán enviados a dos evaluadores anónimos expertos en el ámbito científico sobre el que traten. En caso de discrepancia en los informes, la Dirección podrá enviar el original a un tercer evaluador.

Los evaluadores podrán condicionar su informe favorable para la publicación a la realización de modificaciones que mejoren, a su juicio, el trabajo evaluado. Una vez recibidos los informes de los evaluadores, se rechazará o se admitirá el trabajo para su publicación en la revista.

Para obtener información adicional sobre la política editorial o la preparación de los manuscritos, deben ponerse en contacto con el Director de la Revista o Secretaria del Consejo de Redacción mediante correo electrónico dirigido a la dirección ulepec@unileon.es. 